\title{
Diagnostics of professional challenges as a basis for designing a customized training strategy
}

\author{
Lilia Ibragimova $^{1, *}$, Anna Kandaurova ${ }^{2}$ \\ ${ }^{1}$ EDP Sciences, Nizhnevartovsk State University, 628600, Nizhnevartovsk, Russia \\ ${ }^{2}$ EDP Sciences, Tara Branch of Omsk State Agrarian University, 646532, Tara, Russia
}

\begin{abstract}
Diagnostics of professional challenges of teachers is an important issue for advanced professional training. Current and potential educational needs of modern teachers can only be met through a comprehensive diagnostics of their professional challenges. At the same time, the results of self-analysis and self-diagnostics do not provide comprehensive information for designing a customized training strategy and advanced training programs. The system of current and potential educational needs of teachers is based on the results of selfdiagnostics, self-analysis and reflection, peer review, professional examination, and analysis of legal, scientific and pedagogical sources and socio-cultural context. The identified educational needs of teachers determine the content and structure of a customized educational strategy, are transformed into educational objectives and determine the content of the advanced training programs providing for a continuous education of teachers.
\end{abstract}

\section{Introduction}

Today, the task of developing professional competences is not only imposed on a person himself, but also on the corresponding social institutions [1]. The task of advanced professional training for teachers is reflected in the modern national educational policy. Current national documents regulating teaching activities (professional standard of a teacher, federal state educational standards, and national system of teachers' development) attempt to systematize and apply the requirements of the constantly changing world to the teacher's professional activity to ensure independent, creative, productive learning of students [2]. Professionals involved in planning and teaching in a distributed access environment not only must be well trained in the discipline taught, but also have the skills required for organizing learning activities [3].

Modern research in various fields is characterized by socio-cultural, socio-political, technical and technological changes. Scholars point to the nature and direction of these changes, yet more to the speed, scale, and variability of the transformations in place. Russia's inclusion in all innovative projects and world globalization process, intensive development of an open information society, intensive development of information and digital technologies fail to be timely followed by scientific and educational publications, whereas educational manuals and guidebooks on professional education cannot keep pace with the emerging industrial technologies, discoveries and development of information tools. This context has determined lifelong education as the main principle of the new educational paradigm. In this regard, special hopes are placed on the system of further professional education in both pedagogical science and the pedagogical community.

Peer reviews confirm that about $80 \%$ of the technologies used in the world today become obsolete within two years, and four fifths of all education professionals were trained more than ten years ago. This tendency has determined a new educational paradigm of lifelong learning, which means learning through the whole life. The previous educational paradigm assumed one cycle of professional education and regular advanced training (once every five years), which guaranteed a fullfledged self-realization of a teacher. In addition, it was believed that the number of years spent in the profession meant higher qualifications of a person due to his or her growing experience and competence. Indeed, a few decades ago, technological, regulatory, and productive changes were rather time-consuming, which gave an employee time for adaptation. However, the speed of modern changes taking place in the context of informatization, globalization, development of science and technology is overwhelming. In order to remain in the profession and be successful, a person has to update his or her professional knowledge and skills and improve professional qualifications on a constant basis.

Meanwhile, the system of advanced professional training, with a certain potential due to its efficiency in the short term, fails to meet the needs of the modern pedagogical community or respond to the changes to the extent required, therefore, it does cannot ensure the principle of lifelong education. A teacher, being in a situation of contradiction between the requirements imposed by the state, society and changing conditions of professional activity, is exposed to uncertainty, emotional

\footnotetext{
* Corresponding author: laibra@yandex.ru
} 
stress, and inconsistencies. By its purpose, the system of further professional education (advanced training) is intended to resolve these professional contradictions. The state education policy, reacting and initiating changes in professional pedagogical activity at the federal level, updates the main regulatory documents.

Hence, the system of advanced training, being a component of the overall system of education, is designed to be one of the first to respond to the changing requirements imposed on teachers' activities and to the modern educational challenges. Meanwhile, the system of advanced training today is going through a difficult period, caused by internal reforms and improvement process [4].

Many scholars emphasize that modern system of advanced training fails to meet current and potential educational needs of a modern teacher (L. Gorbunova, E.M. Nikitin, A. Rytov, N.I. Yakovleva). The studies by V.A. Bolotov and V.V. Serikov claim that today's advanced training formats are not aimed at fostering selfconsciousness and analysis of personal professional experience or at motivating for the continuous professional growth among modern teachers $[5,6]$. Thus, a teacher is in a situation where external requirements imposed on his/her activity are growing in proportion to the development of science, technologies, and industries, whereas the emerging educational needs are not satisfied in the formal system of advanced education. Generally, this collision has affected the entire world educational space. As a result, various models of advanced training for modern teachers are being tested both in Russia and abroad [7].

A customized model of advanced training for teachers is a promising model introduced in more than 30 constituent entities of the Russian Federation in 20112014 by the initiative of the Russian Government. When tested and analyzed, the model revealed some problems requiring further consideration. This study discusses one of these aspects, namely, identifying professional challenges experienced by teachers. Unfortunately, teachers often fail to look at their professional difficulties as an opportunity for developing their competence. Rather, they tend to look for external reasons for such challenges (children are unwilling to learn, parents are irresponsible, supervisors are too demanding). Teaching is a highly emotional profession, which is why, according to A.A. Mayer, many teachers experience so-called professional deformation of a personality [8]. At the same time, scholars are sure that the teacher's role in resolving professional contradictions and challenges and developing personal reflection is essential. S.E. Dovbysh believes that nowadays, a teacher's strategy can only be developed through personal reflection of existing professional experience and interpretation of challenges in line with the social and cultural situation [9]. Therefore, identifying and studying professional challenges and transforming them into educational needs of teachers are important objectives for a modern system of professional training. A truly customized training strategy based on current and potential educational needs will allow constructing relevant educational programs, forms and methods aimed at providing continuous education of teachers.

\section{Methodology}

"Professional challenge", when considered in the context of competence approach, is revealed through teacher's professional competence, i.e. it characterizes such a professional situation when a teacher finds it difficult to make a proper decision, which means he/she lacks competence. The pedagogical theory traditionally deals professional challenge of a teacher within the activitybased approach as lack of professional competence for the activity performed (Yu.K. Babansky, N.V. Kuzmina, O.S. Anisimova, T.S. Polyakova et al.). Within the subject and activity-based approach, professional challenge is considered as a result of teacher's reflection of the internal contradiction between the required level of professional competence and its present state and as impossibility to obtain a positive result of professional activity (G.P. Shchedrovitsky, T.N. Savinkova et al.). This view on the concept of professional challenge was reflected in works of N.V. Bordovskaya, A.P. Vinogradova, O.O. Zhebrovskaya, E.A. Koshkina, A.A. Lenkova, O.V. Petrova, O.V. Petunin. These scholars have studied and analyzed professional difficulties of teachers, seeing the challenges as a factor contributing to the improvement of teachers' professional level, on the one hand, and a factor inhibiting teachers' professional growth, on the other hand $[10,11]$.

The following study of current and potential professional challenges of teachers is based on the need and information-based approach aimed at identifying basic significant needs of the trained persons and searching for information, mechanisms, means, and conditions to satisfy such needs (G.M. Bradik, P.M. Ershov, G.K. Zaitsev, R.R. Ismagilova, P.V. Simonov et al.).

According to P.V. Simonov and his colleagues who developed the basics of the need and information-based approach in line with the theory of emotion psychophysiology, the methodological essence lies in the subjective assessment of the chances for satisfying the emerging educational requirements and comparing information about the means and ways to meet such requirements. Various researchers of P.V. Simonov's school (G.M. Bradik, P.M. Ershov, G.K. Zaitsev, R.R. Ismagilova, etc.) have recently studied the educational capabilities and potential of the need and informationbased approach in their theses. The scholars believe the need and information-based approach to have an obvious interdisciplinary status in the human sciences because it allows one to examine and study human behavior in the coordinate system of "human needs and possibilities to satisfy them in interaction with the social and natural environment".

The practical design of a teacher's customized training strategy is implemented in line with the subject-activity approach (K.A. Abulkhanova-Slavskaya, L.I. Antsyhirova, A.V. Brushlinsky, T.I. Zaslavskaya, S.L. Rubinstein, etc.).

Many scholars note that, against the background of paradigmatic transformations, an internal system resource for the development of national pedagogical science and the education system is being formed, thereby overcoming "subjectless" nature and demonstrating the 
ability for self-development. The ability for selfdevelopment is the most important parameter of subjectivity. A.I. Rytov, in his concept of a subjectoriented system of further teacher training, has substantiated the role of a teacher being a subject of improving his or her own competences. Designing a customized training strategy responds to all parameters of subjectivity, including transformative activity in response to needs; reflection as a necessary condition for changing personality and environment; freedom of choice and responsibility for such choice; self-development as a necessary condition for effective life and activity. Consequently, the use of a subject-activity approach to the professional development of teachers is dictated by the principle of recognizing a person as an active subject of all forms of his or her voluntary activity. This approach allows us to see teachers as active transformers of their own activities and the environment around them, with a potential for self-determination, self-development and self-change when influenced by changes in the environment. The subject-activity approach does not appeals to the activity directly, but rather it does so indirectly, by appealing to the activity of the subject, which is justified by the scholars of S.L. Rubinstein's research school.

The authors used the methods of survey, self-analysis, observation, expert evaluation, discourse analysis, and content analysis.

\section{Research}

The problem of updating the system of advanced training as a social system currently failing to meet the needs of teachers was discussed by Russian pedagogical researchers I.Yu. Aleksashina, S.V. Alekseev, N.S. Bugrova, L.N. Gorbunova, R.S. Dimukhamedov, T.L. Dubrovina, E.M. Nikitin, A.I. Rytov, G.A. Safarova, O.V. Surodina, S.V. Khachirov, N.I. Yakovleva, et al. Foreign scholars, including Van der Heijden, J. Kelly, S. Cherkowski, T. Kleickmann, K.E. Johnson, P.R. Golombek and other researchers also paid attention to current problems of further training for teachers. These studies suggest that there is a need to develop teacher's personal attitude to resolving professional challenges and meeting the objectives of his or her continuous professional growth. Our study is based on the philosophical idea put forward by G.P. Shchedrovitsky who sees advanced training not only as a process (continuous, educational, and specially organized), but also as a personal activity [12]. A.A. Mayer also emphasizes the dominant role of a person in actualizing the internal resources to minimize and compensate for sustained professional deformations [13]. Russian psychology scholars have developed certain measures aimed at preventing and correcting professional deformations of teachers. The priority is given to activating personal attitude and internal resources by boosting the competences, developing reflection and selfregulation, ensuring personal growth and undergoing advanced training [14]. In line with the subject and activity-based and need and information-based approaches, we have developed a mechanism for diagnosing professional challenges. This mechanism is used to develop a system (maps, matrix) of teacher's educational needs serving as a basis for a customized training strategy [15]. This mechanism includes five stages: self-analysis, self-diagnostics, professional examination, expert evaluation, career portfolio. The mechanism can be uploaded on a digital platform of an advanced training school and accessed automatically and remotely.

At the first stage of self-analysis, teachers analyze their actions in accordance with standards in order to identify professional challenges. Our study showed that more than half of teachers $(56 \%)$ are unable to identify their professional difficulties; $34 \%$ of teachers are unable to identify and select the content of advanced training to meet their challenges.

At the second stage of self-diagnostics, or on-line diagnostics, teachers are given automated diagnostic procedures to assess their level of major professional competencies (psychological, pedagogical, subject and methodological). The study showed that this stage is more informative, allowing teachers to identify both current and potential challenges more accurately. Despite the fact that there were much fewer people willing to go through this stage (134 teachers, i.e. $62 \%$ of all tested), selfdiagnostics allowed identifying the following professional challenges in teaching: teaching children with special educational needs (children with disabilities, gifted children, children with deviant behavior), addressing parents, mastering and applying new educational technologies. It is noteworthy that no problems were identified as far as the subject or methodological competences were concerned.

Subject, methodological, psychological, pedagogical, and communicative competencies of teachers), confirmed the following professional challenges: first, professional difficulties in designing the educational process (including those in accordance with the federal state educational standards); second, challenges in developing and applying educational technologies; third, difficulties in organizing social education for various categories of students. At this stage, professional challenges of teachers not only concerned the design of the study programs, but also the design of aims and objectives. For instance, teachers often fail to articulate the aim of a study course, module, or class, or to set objectives via design of personal and metasubjective learning outcomes. Most surveyed teachers $(69 \%)$ had difficulties with designing the content of a school discipline, since the traditional calendar-thematic planning of the educational content following textbook paragraphs no longer meets the requirements of modern federal state educational standards. The diagnostics revealed that teachers experience challenges in selecting the content of a school discipline, namely: difficulties in identifying the main subject (43\%); in determining the axiological component (when knowledge is not for the sake of knowledge, but knowledge as a means of personal development of students) (52\%); in following the principles of science and accessibility, integration and differentiation of metasubject content through the definition of links with other academic subjects (64\%). More than half of the surveyed (57\%) had professional difficulties in designing 
test and measurement materials for their subject. For instance, many teachers had difficulties in designing differentiated assessment of students' personal achievements (46\%); reflecting the interdisciplinary links and continuity in the measuring and control materials (67\%); justifying the given mark in terms of correctness, independence, originality of the student's answer (67\%).

Professional challenges in developing and applying the educational technologies are manifested, on the one hand, in the desire to use traditional methods (explanation, oral survey, knowledge consolidation in task-solving) $(38 \%)$, on the other hand, in excessive enthusiasm for individual technologies (design or game technologies, etc.) $(43 \%)$. Based on the didactic principle of harmonious balance of teaching methods, one should consider the individuality of each teacher and the specifics of the subject taught. However, mastering various teaching methods and technologies surely expands the teacher's didactic arsenal and creates new prospects for improving the quality of education.

Difficulties in organizing social education of various categories of students were the most common (for $88 \%$ of the respondents). Traditional mass school is known for the stereotype of "universal" educational activities, thus, insufficient knowledge in developmental psychology and educational psychology are the main reasons for such professional challenges among teachers. Therefore, the task of organizing joint activities for children with disabilities and intellectually talented children is a regular challenge for teachers, who often fail to provide complete psychological and pedagogical characteristics of different categories of children.

Next stages (expert evaluation; career portfolio), though optional, can reveal significant information about the teacher's professional level and prospects for professional growth. Thus, by studying the personal portfolio of a teacher one can obtain information about the strongest aspects of his or her professional activity.

These stages may become a part of teacher certification procedure and regional personnel policy and be used to develop a succession pool of teachers. For implementing the actions within these stages, experts require special training in all professional aspects of pedagogical activity (subject, psychological, pedagogical, methodical, educational, skill-developing). At the same time, a differentiated examination of the professional challenges experienced by teachers at each stage is an exceptional informational basis for designing the content and forms of advanced training for practicing teachers.

Such complex diagnostics and data accumulation will allow an advanced training school to develop an information system (map, matrix) of the teacher's educational needs and define the strategy for advanced training and development of local teaching community. The collected data displaying typical professional challenges encountered by teachers, contribute to designing the content of advanced training relevant to current educational needs. It should be noted that S.E. Dovbysh has previously discussed event-resource mapping as an optional didactic means for designing the professional development pathway [15].

Being the subject of pedagogical activity, a teacher gets a map of his or her personal educational needs serving as a basis for a specific teacher's customized training strategy. Let us consider the following map of educational needs for a chemistry teacher's (with higher education diploma and 15 years of working experience) developed into a customized training strategy as an example:

1) 2019: boosting theoretical knowledge in chemistry, solving sample chemical problems for the unified state examination, solving sample school Olympiad competition problems, designing and developing tests and evaluation tools.

2) 2020: boosting knowledge in information and digital technologies, developing innovative educational technologies to be further used in teaching.

3) 2021: preparing for certification, taking part in a professional competition, boosting theoretical knowledge in education and social development.

The data on professional challenges of teachers, based on self-analysis and self-diagnostics, is insufficient for the strategic planning of further professional development. When evaluating the encountered professional challenges, most teachers resort to the operational and tactical evaluation. In order to apply the principle of continuing education, one requires strategic evaluation ensured by the prognostic function of the advanced training system. Predicting professional difficulties of teachers and strategic planning of the advanced training content require an analysis of the current sociocultural context, studying federal and regional educational policy, and understanding the public social service commissioning. To identify the challenges at this level, we can analyze the documents and pedagogical research publications, apply a critical discourse analysis and critical content analysis of published materials. Via segmenting the changes taking place in modern Russian society and culture, we are able to identify certain educational problems which teachers fail to see as actual educational needs, and yet, they are potential needs and challenges indeed. This happened, for example, to dynamic social stratification and migration, which at first were not seen as challenges in education, but were widely discussed in sociology and by media. Only a few decades passed before they caused significant transformations in education, producing new categories of students (migrant children, bilingual children, children with special educational needs, etc.) and new phenomena (elite education, distance education, inclusive education, etc.). Therefore, when it comes to the system of advanced teacher training, it is important to predict the educational needs of teachers with an account for the current social and cultural context.

\section{Conclusion}

Professional challenges encountered by a teacher serve as the basis for designing a customized training strategy for continuous professional development. The diagnostics of educational needs is effective when accompanied by selfdiagnostics and self-analysis, expert evaluation and forecast of probable professional problems and challenges, with an account for the general social and cultural situation.

The design of a customized training strategy should include all levels of information about the teacher's current and potential educational needs. The personal 
approach is ensured via self-conscious analysis of professional challenges and educational needs, as well as via freedom to choose the content, format and terms of advanced training. Diagnostics of professional challenges experienced by teachers ensures their effective professional development and also facilitates the ability to predict and prevent such challenges in teaching.

When tested, the technology of customized training strategy in the system of advanced teacher training has showed high results: $100 \%$ of teachers who took part in the test pointed to high mobility and availability of the technology. $86 \%$ of teachers confirm that their current educational needs have been satisfied; $68 \%$ of teachers confirmed that their prognostic educational needs have been satisfied. $74 \%$ of the tested have shown a decrease in emotional and psychological stress in their professional activities. Judging from the point of view of the advanced training system, designing a customized training strategy at each stage is highly informational, starting from the stage of identifying educational needs and ending with the stage of selecting the educational resources. The analysis of the teachers' project activities has revealed deficiencies in the use of informal resources and insufficient level of information and communication competences as objects of further scientific research.

\section{References}

1. G.R. Eremeeva et al., "Pedagogical conditions necessary for training teachers to manage the development of intellectually gifted students," Advances in Social Science, Education and Humanities Research (ASSEHR), 97, 37-41, (November 2017).

2. L. Ibragimova, I. Skobeleva, "Conditions for creation and development of media culture in students of secondary professional education", Mediaobrazovaniye, 1, 89-94. (2018).

3. L.A. Ibgragimova, I.E. Skobeleva, Electronic educational resources as an essential element ensuring qulaity of future middle ranking professionals, Vestnik Nizhnevartovskogo gosudarstvennogo universiteta, 3, 16-20, (2017).
4. L.N. Gorbunova et al., A model of advanced training for teachers with related training in information and communication technologies, Vestnik Moskovskogo gosudarstvennogo universiteta kultury i iskusstv, 6, 117-121, (2008).

5. V.A. Bolotov, To the reforms in pedagogical education, Psikhologicheskaya nauka i obrazovaniye, 19, issue 3, 32-40, (2014).

6. V.V. Serikov, Personal development education as a culturological educational model, Izvestiya Vogogradskogo gosudarstvennogo pedagogicheskogo universiteta, 2 (106), (2016).

7. V.Ya. Sinenko, A modern model of advanced training for education professionals, Professionalnoye obrazovaniye v Rossii i za rubezhom, 1(1), 91-93, (2009).

8. A.A. Mayer, Profesional deformations of preschool teachers, 128, (2015).

9. S.E. Dovbysh, Customized pathway of teachers' professional growth: problem statement, Upravleniye obrazovaniyem: teoriya i praktika, 2 (30), 5-11, (2018).

10. O.V. Petunin, Professional challenges of teachers in the course of introducing Federal State Education Standards of General Education, Sovremenniye problemy nauki i obrazovaniya, 1, (2016).

11. A.P. Vinogradova, Study of professional challenges encourntered by teachers in basic school, Sovremenniye problemy nauki i obrazovaniya, 4, (2015).

12. G.P. Shchedrovitskiy, A system of pedagogical studies: a methodological analysis, Pedagogika i logika, 16-22, (1993).

13. A.A. Mayer, Personal development of teachers as a way to prevent professional challenges in higher educaiton institution, Vestnik RMAT, 3, 94-99, (2016)

14. E.F. Zeer, Profession psychology, 306. , (2003).

15. S.E. Dovbysh, "Event-based approach to the teacher's work: The open educational technology «EventResource Mapping»", Education Management: Theory and Practice, 4(28), 7-29, (2017). 